Journal: Early Childhood Education Journal

Original Paper/Research Article

\title{
Home learning environment and Concept Formation: A family intervention study with kindergarten children
}

\author{
Frank Niklas, Caroline Cohrssen \& Collette Tayler
}

Melbourne Graduate School of Education

University of Melbourne

Running head: HOME LEARNING ENVIRONMENT \& CONCEPT FORMATION

Corresponding author:

Dr Frank Niklas

Melbourne Graduate School of Education

University of Melbourne

Level 4, 100 Leicester Street

VIC 3010 Australia

Tel: 00613/90356723

Email: frank.niklas@unimelb.edu.au 
Dr Caroline Cohrssen

Melbourne Graduate School of Education

University of Melbourne

4/100 Leicester Street

Melbourne, Australia

VIC 3010

Tel: +61 390354441

Email: ccoh@unimelb.edu.au

Professor Collette Tayler

Melbourne Graduate School of Education

University of Melbourne

4/100 Leicester Street

Melbourne, Australia

VIC 3010

Tel: +61 383340992

Email: collette.tayler@unimelb.edu.au 


\begin{abstract}
:
Children's cognitive development has a neural basis, yet children's learning is facilitated by interactions with more knowledgeable others. Young children experience such interactions in the context of the home learning environment (HLE), when parents support children's thinking and learning during everyday activities. Consequently, one way to improve children's cognitive abilities may be to enhance the quality of the HLE. In this study a nonintensive intervention was developed to improve both HLE and children's cognitive abilities. The sample consisted of 113 Australian 4-year-old children and their parents. All parents were invited to participate in a two-part intervention that included firstly attending a group meeting at which information regarding the HLE was provided, and secondly participating in an additional individual session that introduced the principles of counting and dialogic reading. HLE and children's Concept Formation, as an indicator of fluid reasoning, were assessed before and after the intervention. Families and children in the intervention group showed significantly greater gains in both, the quality of HLE and children's Concept Formation than members of the control group. Results indicate that non-intensive family interventions may positively impact on HLE and children's fluid reasoning.
\end{abstract}

\title{
Key words:
}

Home Learning Environment (HLE); Concept Formation; fluid reasoning; non-intensive intervention; preschool children; Australian sample

\section{Home learning environment and fluid reasoning:}

\section{$\underline{\text { A family intervention study with kindergarten children }}$}

\section{Abstract:}


Children's cognitive development has a neural basis, yet children's learning is facilitated by interactions with more knowledgeable others. Young children experience such interactions in the context of the home learning environment (HLE), when parents support children's thinking and learning during everyday activities. Consequently, one way to improve children's cognitive abilities may be to enhance the quality of the HLE. In this study a non-intensive intervention was developed to improve both the HLE and children's cognitive abilities. The sample consisted of 113 Australian 4-year-old children and their parents. All parents were invited to participate in a two-part intervention that included firstly attending a group meeting at which information regarding the HLE was provided, and secondly participating in an additional individual session that introduced the principles of counting and dialogic reading. The HLE and children's Concept Formation, as an indicator of fluid reasoning, were assessed before and after the intervention. Families and children in the intervention group showed significantly greater gains in both, the quality of the HLE and children's Concept Formation than members of the control group. Results indicate that nonintensive family interventions may positively impact on the HLE and children's fluid reasoning.

Keywords: Home learning environment (HLE); Concept Formation; fluid reasoning; nonintensive intervention; preschool children; Australian sample 


\section{Introduction}

The ability to reason, form concepts and solve problems, whilst simultaneously incorporating novel information and rules can be described as fluid reasoning ( $\mathrm{Au}$ et al. 2015). The importance of children developing problem solving skills and processes is a key tenet of the Early Years Learning Framework for Australia (Department of Education, Employment and Workplace Relations 2009). The pedagogical implications are apparent: fluid reasoning is a critical component of intelligence and consequently important for later academic success (Schneider et al., 2014). Research shows that fluid reasoning is closely associated with both, mathematical and literacy skills (Evans et al. 2001; Floyd et al. 2003). Learning begins long before children start formal school-based education.

Interventions that focus on connecting new concepts with prior knowledge, that use demonstrations and guided practice, and provide feedback on performance appear to make a difference for children's development (Klauer et al. 2002). A significant association has been found between children's gains in fluid reasoning and their attendance of 'high dosage' early childhood education and care programs that delivered play-based learning activities underpinned by unambiguous learning concepts (Cohrssen et al. 2014). Such interventions may also be implemented in the home learning environment (HLE) where a child typically spends significant amounts of time in the early years, actively interacting with his or her parents (Lukie et al., 2014). The HLE has proven to be a significant predictor of young children's abilities such as literacy (e.g. Niklas and Schneider 2013; Sénéchal and LeFevre 2002), numeracy (e.g. Anders et al. 2012; Niklas and Schneider 2014) or even behavioural outcomes (e.g. Schmiedeler et al. 2014).

Few studies have focused on the association between the HLE and fluid reasoning as an indicator of cognitive ability. In addition, few attempts have focused on supporting parents to create a favourable HLE for their children in order to enhance their fluid reasoning. This 
study introduces a non-intensive intervention in the HLE and explores the effects on both, the HLE and children's concept formation as an indicator for fluid reasoning.

\section{Improving children's cognitive abilities}

Intelligence is the psychological construct that has been studied most, and whilst the stability of cognitive ability is fairly high from school age onward, there is much fluctuation and change in children's demonstrated intelligence when measured with standardized assessment instruments during the pre-school and kindergarten years (e.g. Schneider et al. 2014; Watkins and Smith 2013). Induction and fluid reasoning skills form a key component of such measures of intelligence. Here, a person is required to reason, form concepts and solve problems, whilst recognising underlying rules by detecting regularities and making generalizations by comparative processes (Klauer et al. 2002).

Whilst children are born with innate abilities (Gelman and Butterworth 2005), what children learn is also determined by their interactions with people, objects and events in their environment (e.g. Cooke and Buchholz 2005 cf. Vygotsky 1978). Great variation exists in the environments in which children live and grow, yet play and human relationships form the common context for children's learning and for advancing their thinking. Consequently, the relational processes that occur when young children engage with others build a platform for advancing children's fluid reasoning skills, and in this way influence academic learning (cf. Klauer 1996).

Certainly, interventions have been used successfully in training studies that promote children's cognitive abilities (e.g. Au et al. 2015; Klauer et al. 2002). For instance, Klauer and colleagues (2002) implemented a five-week training program which involved two 45minute training sessions each week. During these sessions, small groups of children were taught a three-step process involving recognizing and differentiating between different types 
of problems, finding appropriate solutions to the problems, and checking their solutions. In addition, the researchers attempted to teach the children to transfer their problem-solving strategies, as appropriate, to other problems they encountered. The findings indicate that the intervention improved performance on inductive tasks and to a lesser extent, on noninductive tasks as well.

Such results have often been replicated. In a meta-analysis that included 74 intervention studies, an average effect size of $d=.52$ was found for the improvement of performance in intelligence tests (Klauer and Phye 2008). Training that targeted inductive and fluid reasoning led to positive long-term effects on fluid intelligence and to positive transfer effects on academic performance.

\section{Home learning environment and children's cognitive abilities}

Joint problem solving is central to the socialization process (Gauvain 2001), and shared interactions of this nature are apparent from birth, at times initiated by the infant and at other times by the caregiver. As a child's understandings and independent skills develop, interactions with others evolve and typically, adults scaffold children's learning and abilities (Vygotsky, 1978). Cognitive development is thus both an individual and a social process: in the context of the home environment, by jointly attending to matters and solving problems in conjunction with more knowledgeable others, children develop understandings that become the foundation of knowledge and dispositions toward further learning, and future problem solving.

One context for such social processes is the HLE. In comparison with other more distal family characteristics known to influence child development, such as socio-economic status (SES) or migration status, the HLE as a child's primary learning environment is more readily manipulated (Molfese et al. 1997). Several studies have focused on family literacy programs, 
showing that interventions in the home literacy environment are successful in enhancing children's literacy abilities (e.g. Niklas and Schneider, 2015; Sénéchal and Young 2008). Some studies have investigated the impact of supporting mathematical competencies in the home learning environment (e.g. Niklas et al. in press; Sheldon and Epstein 2005; Starkey and Klein 2000), but few studies have focused on the association of the HLE with cognitive abilities such as fluid reasoning.

Correlations between the HLE and intelligence reported in studies that focused on literacy or numeracy learning reflect small to medium effect size associations (e.g. Kleemans et al. 2012; Niklas \& Schneider 2013). In a recent analysis by Frumkin (2013), the HLE proved to be a significant predictor of the Bracken Basic Concept Scale, explaining about $11 \%$ of variance for three year old children (see also results of Bradley and Caldwell 1980). In addition, Molfese et al. (1997) showed that the early HLE was an important predictor of children's intelligence, even when controlling for SES and biomedical risk conditions. Given firstly that interventions in the context of the HLE supported children's literacy, numeracy and behavioural development, and secondly that fluid reasoning can be trained, one may expect a high quality HLE characterised by supportive parent-child-interactions to be associated with children's cognitive development as well.

\section{Research focus}

Although the impact of the HLE on precursors of numeracy and literacy acquisition has been explored in several studies (e.g. Anders et al. 2012; Niklas \& Schneider 2013, 2014), little is known about the impact of the HLE on more general cognitive skills such as fluid reasoning. The question also remains what kind and how much intervention may be sufficient to improve the learning environment and thereby enhance cognitive competencies of children living in these environments. 
To explore these questions, we conducted a non-intensive intervention study in one local government area in the city of Melbourne, Australia. The study was designed to increase the quality of interactions between parents and children in the home learning environment by equipping a subsample of parents with knowledge of (1) the importance of the home learning environment, and (2) the principles of counting and dialogic reading. We assumed that an intervention of this nature may be sufficient to increase the instructive quality of the HLE and better support children's fluid reasoning when compared with families not participating in the intervention.

\section{Method}

$\underline{\text { Sample }}$

All 113 participating children attended one of four early childhood education and care (ECEC) centres located in one municipal area of Greater Melbourne, Victoria. After obtaining approval from local government, formal consent to conduct the study was obtained from the respective centre coordinators, directors and kindergarten teachers. In addition, the project had been approved by the Human Research Ethics Committee of the University of Melbourne (Ethics ID: 1341202.2). Each family with a child attending the program catering for children in the year prior to commencing formal school education was invited to participate in the study. Members of the research team were on hand at the start of the academic year to obtain consent from parents and caregivers and to answer questions at times when parents or family members brought their child to the centre or collected them at the end of the day.

Boys (57.8\%) outnumbered girls (42.2\%) in the sample, with a mean age of approximately 4 years and 5 months $(S D=3.9$ months $)$ at t1. About $9 \%$ of the sample spoke a language other than English as the main language at home. In $38.5 \%$ of the sample, at least 
one of the parents, or the child, was born outside Australia. However, when participants born in a country in which English is an official language are excluded from the migrant group, the overall percentage decreases to about $22 \%$. The highest level of education in a household was in most cases a university degree. However, about $15 \%$ of the households in the sample had either almost no schooling, had completed Year 10 or 12 , or had a TAFE ${ }^{1}$ certificate as their highest level of education.

The first-round assessment of children took place in the kindergarten rooms during February and March (t1). Second-round assessments were conducted between mid-July and mid-September (t2). Each round of assessment took approximately five to six weeks to complete.

Seven children were withdrawn from their centres between $\mathrm{t} 1$ and $\mathrm{t} 2$; one of these children was in the intervention group. This subsample of seven children did not differ significantly from the remaining children in regard to sex, age, migration background, main language, parental education, HLE, and children's fluid reasoning skills (t-tests; all p's > $.05)$.

\section{Assessment of fluid reasoning}

The Woodcock-Johnson III 'Concept Formation' subtest was selected from the battery of tests of cognition to assess children's fluid reasoning skills (WJIII; Mather \& Woodcock 2001; McGrew et al. 2001). The Woodcock-Johnson III is a standardized, normed measure of cognition frequently used to measure children's cognitive abilities (e.g. Howell \& Kemp 2010).

\footnotetext{
1 Acronym for Technical And Further Education institutions; providers of vocational education and training
} 
The Concept Formation tasks require rule application and frequent switching from one rule to another. It is a broad measure of the ability to reason, form concepts and solve problems, using unfamiliar information or novel procedures. For each presented item, the child tries to determine the rule that distinguishes a set of symbols into two groups. Differing from other assessment tasks, the child receives feedback on performance during the Concept Formation test and if errors are made, correct responses are pointed out and explained (Median Test Reliability $=.94)$.

\section{Primary caregivers' participation}

Coinciding with the periods of child assessments, primary caregivers were requested to complete surveys about child and family characteristics and the home learning environment. Parents were requested to report on various aspects of the HLE (see Appendix). HLE was measured by 10 questions that focused on cognitive activities at home (for example, 'We often play memory or thinking games at home (such as Concentration or Snap)'), numeracy activities (for example, 'How often do you play games with your child that involve dice?'), literacy activities at home (for example, 'At home, we often talk about things we have read'), and parents' teaching of mathematical or literacy concepts (for example, 'At home, I often explain to my child how to do simple sums or how to divide, for example, apples among people or a cake into pieces').

Each item was rated on a five-point scale (for example, 'several times a week' to 'never' or 'very true' to 'not true'). Values of 4 to 0 were accordingly assigned. Ninety-two parents returned the survey at $\mathrm{t} 1$ and the sum score was a reliable measure of the home learning environment (Cronbach's $a=.74$ and $.63 ; r_{t t}=.64$ ) with a mean score of $M=25.7$ and $S D=$ 6.3 and observed values ranging from 9 to 40. 
Seventy parents returned the survey at $\mathrm{t} 2$. In addition to the questions on the HLE, parents who took part in the intervention were asked to answer questions on the intervention and whether it changed the way they had approached instructing their children at home.

\section{$\underline{\text { Intervention }}$}

Immediately after the baseline child assessments were completed, primary caregivers/parents of participating children were invited to attend a parents' information evening held after hours at each of the four ECEC centres. Of the 113 children participating in the study, the parents of 37 children attended an information session. At each parents' evening, the lead researchers delivered a 40-minute PowerPoint presentation that (1) discussed the importance of supporting children's numeracy and literacy skills in the home environment in general, and how to engage in meaningful interactions with their child that foster thinking and learning; (2) provided a hand-out which offered suggestions about how to support emerging child skills in a purposeful manner; and (3) invited those parents present to take part in an individualised session with their child at a later date. This later session included playing a dice game and reading a children's book. All parents accepted this invitation. Parents who did not attend the parents' evening were not invited to take part in the individualised session. Suggestions about supporting children's emerging skills included playing word, rhyming, dice, number and memory games, having frequent conversations with the child, visiting libraries regularly, practising using numbers in everyday life, and demonstrating that we use mathematical thinking often in everyday life. In addition, parents were reminded that they act as models for their child and that the child is likely to copy their behaviour and adopt their attitudes.

The individualised sessions were held at the children's ECEC settings and each lasted approximately 30 to 45 minutes. At this session, each child received a dice-based counting 
game, and parents received coaching on supporting their child's emerging mastery of the counting principles, and were provided with a handout on the game (Gelman and Gallistel 1978). The dice game required each player to roll a die, identify the number rolled, and count a corresponding number of coloured counters from a pile in the centre of the table. Results were then compared between players and children were required to think about concepts such as 'more than', 'less than' and 'the same as' and articulate their reasoning. Each child also received a copy of a popular children's storybook (Dodd 1983, 'Hairy Maclary from Donaldson's Dairy'). Parents read the book with their children and were observed during this reading session. They then received feedback on their reading, along with coaching on how to enact the key aspects of dialogic reading with their child. Examples of dialogic reading strategies include encouraging the child to complete the blank at the end of a sentence when the adult pauses in a meaningful manner, asking questions about the book and encouraging the child to recall and retell the story, encouraging the child's higher order thinking by asking 'wh-questions', and linking the story with the child's personal lived experience (Cohrssen et al. in press; U.S. Department of Education 2006). This approach uses the content of the story as the platform for back-and-forth dialogues between parent and child and thereby provides opportunities for questioning that encourage children to engage in rich and complex thinking (Doyle and Bramwell 2006).

For the purposes of this study, the 'intervention group' includes those children whose parents attended the parents' evening and in addition, participated in the individualised session. The non-intervention group includes those children whose parents did not attend the parents' evening and consequently did also not take part in the individualised session. The study design is not experimental as families self-selected into these groups. However, participating and non-participating children and families did not differ significantly in child age, sex, main language or Concept Formation at $\mathrm{t} 1$ (t-tests; all $p$ 's $>.05$ ). In addition, they 
did not differ in parental education level, parental interest in children's schooling, the HLE and migration background (t-tests; all p's > .05).

\section{Results}

Table 1 provides an overview of the correlations between all variables as well as descriptive statistics for HLE and Concept Formation.

- Please insert Table 1 about here -

Boys in the sample were older than girls and older children showed greater performance on Concept Formation. Both, the highest parental education in the household and children's main language were not significantly associated with the other variables. However, children speaking a language other than English as the main language tended to be boys in this sample and showed a tendency to live in a more favourable HLE at t2. Finally, HLE was significantly associated with children's Concept Formation and the correlations between measures $(r=.20-.33)$ indicate small to medium effect sizes.

In a second step, we analysed whether the intervention had some effect on the home learning environment. First, we checked at $\mathrm{t} 1$ whether parents in the intervention group planned to change their HLE, taking the information provided at the parents' evening and the individual sessions into account. In addition, these parents were asked at $\mathrm{t} 2$ whether the received information changed the way they had interacted with their children. Of the intervention parents, $89 \%$ planned to change their HLE to incorporate the information they were provided, more than $80 \%$ indicated that they had adapted their approach to supportive activities at home.

We then calculated analyses of variance with repeated measurements for the overall HLE to test for differences between the participating and non-participating group in the development of the HLE. There was a significant effect of time with $F(1,53)=23.22(p<$ 
$\left..001 ; \mathrm{y}^{2}=.31\right)$. Independent of the intervention, families in the sample improved their HLE between $\mathrm{t} 1$ and $\mathrm{t} 2$ as indicated in the means (see Tab. 1). The interaction between intervention and time was also statistically significant with $F(1,53)=8.29\left(p<.01 ; \eta^{2}=.14\right)$ showing that the intervention and the non-participating group differed in the change of the HLE between $\mathrm{t} 1$ and $\mathrm{t} 2$. As can be seen from Figure 1, both groups improved their HLEs. Whereas there was no significant difference between both groups in regard to their HLE at $\mathrm{t} 1$, there was a marginally significant difference between them at $\mathrm{t} 2(\mathrm{t}(67)=1.77 ; p<.10 ; d$ $=.44)$. Consequently, both groups not only differed significantly in their development of HLE with the intervention group showing a difference of about 4.5 points in comparison with about 1 point in the non-intervention group (large effect size), but the intervention group also tended to provide a more favourable HLE at t2 (small to medium effect size).

- Please insert Figure 1 about here -

As a last step, an analysis of variance with repeated measurements for Concept Formation was conducted, with child age and sex as control variables (repeated-measures ANCOVA). There was no significant effect for time or the control variables (all $p$ 's $>.05$ ). However, a statistically significant interaction (small to medium effect size) between time and intervention group was found; $F(1,102)=5.80\left(p<.05 ; \mathrm{y}^{2}=.06\right)$. Figure 2 presents the development of Concept Formation for both groups controlled for sex and age.

- Please insert Figure 2 about here -

As can be seen in Figure 2, children in both groups demonstrated gains in Concept Formation. However, after starting at about the same level, children in the intervention group clearly showed a steeper 'growth' slope. On average, children in the intervention group scored significantly higher (about 2.5 points) on the Concept Formation task than children from non-participating families at $\mathrm{t} 2(\mathrm{t}(107)=2.63 ; p<.05 ; d=.52)$. 


\section{Discussion}

Families are children's first educators, nonetheless the frequency with which parents engage in conversations with children that support and extend understanding of concepts varies (Gunderson and Levine 2011). Research shows that the home learning environment is closely associated with early child competencies and is a significant predictor of children's development of literacy and numeracy abilities (e.g. Anders et al. 2012; Niklas and Schneider 2013). This varying support of children by their parents leads to differences in children's abilities, even before they start school. Thus early cognitive differences in measures of intelligence can also be observed (Schneider et al. 2014).

In this study, a non-intensive intervention targeted the HLE provided by families. The intervention consisted of a discussion of the importance of the home learning environment in general as well as the provision of (1) general suggestions on how to support children's thinking and learning during everyday interactions and of (2) specific activities that focused on the principles of dialogic reading and counting. Both latter activities encouraged children to analyse information (whether the content of a story or the counters they had 'won'), to evaluate the information, and to explain and justify their thinking - in short, to rehearse reasoning skills that support children's cognitive development. Our conceptualization of the HLE sets this study apart from many other studies, most of which focussed either on the home literacy or the home numeracy environment (e.g. Kleemans et al. 2012; Sénéchal and LeFevre 2002). We regarded literacy and numeracy as key elements of the HLE but cast a wider net to include more general activities that support children's problem solving and reflective thinking as well, such as memory games.

We found that our measure of the HLE was significantly associated with our indicator of children's fluid reasoning. This aligns with earlier studies that found the HLE to be an important predictor of children's intelligence (Frumkin 2013; Molfese et al. 1997). Clearly, 
the way parents interact with their children at home influences children's problem solving, hypothesising and reflective thinking skills, all of which are learning outcomes prioritised in early childhood education (DEEWR, 2009).

Family interventions have been demonstrated to improve both children's literacy and the home literacy environment (Niklas and Schneider 2015; Sénéchal and Young 2008) and children's numeracy abilities (Niklas et al. in press; Sheldon and Epstein 2005). Interventions in the school context have improved children's fluid reasoning (Klauer et al. 2002), but few interventions have targeted families and the home environment to improve children's cognitive competencies.

Our approach provided unambiguous counting and reading strategies for parents to use with their children at home. These strategies were achievable, regardless of the parents' level of education or English language skills. The strategies provided parents with examples of prompts and questions to ask during playful storybook reading and counting game activities; the prompts and questions were, however, purposefully designed, firstly to encourage children to engage in higher order thinking that supported their concept formation and transferral of knowledge from one context to another, and secondly to require children to articulate their thinking. The results reported in this study demonstrate that even a nonintensive intervention with families may be effective, firstly in improving the HLE and secondly, in supporting children's developing cognitive skills. Our findings were observed within 20 weeks, potentially changing the children's learning trajectories.

Further research is necessary to explore how exactly families applied the intervention at home in order to increase the quality of the HLE, and also to explore the extent to which children's gains in Concept Formation were sustained throughout the year prior to commencing school. In addition, some improvement of numeracy and literacy abilities may 
be observed as gains in cognitive skills often lead to transfer effects (cf. Klauer and Phye 2008).

Meta-analyses of intervention studies demonstrate that specific instructions, contingent responses and questioning of children contributed to larger learning effects than other forms of intervention, and that short periods of intervention often lead to larger effects than longer interventions (Kroesbergen and van Luit 2003; Swanson and Hoskyn 1998). Our results support this. In addition, our results also align with the findings of intervention studies on fluid reasoning for which a mean effect size of $d=.52$ was found (Klauer and Phye 2008).

This study has some limitations. Firstly, there was no random assignment of participants and thus no formal control group. No 'waiting-list' control group could be used due to limited resources and a small sample size. Consequently, comparisons were only possible for participating versus non-participating families. This non-random design implies that there might have been a selection effect. However, we tested for initial differences between the groups and we controlled for age and sex when comparing children's development of Concept Formation. No statistically significant differences between the groups at $\mathrm{t} 1$ were found, indicating that participating and non-participating families were very similar at the beginning of the study. Nevertheless it is possible that some unobserved differences between participating and non-participating families may have influenced the findings.

Secondly, the HLE was assessed via self-report. Using a survey poses the risk of perceived social desirability affecting responses. However, previous studies on the home learning environment showed that this kind of assessment procedure often provides reliable data and leads to findings that are closely related to those found with other measures (cf. Burgess 2002). In addition, not all parents completed surveys. Consequently, analyses regarding the HLE could only be done for a reduced sample. Nonetheless, a significant large effect of the intervention on the HLE was found, and this result aligns with the findings 
relating to children's development of Concept Formation that were analysed for the whole sample.

Finally, no long-term effects were analysed. It would be of interest to test whether the intervention has any long-term transfer effects as research indicates that improved fluid reasoning leads to such transfer effects (Klauer and Phye 2008).

Despite these limitations, this study has several strengths. It is one of the first studies targeting the HLE provided by parents in regard to children's learning and cognitive abilities. Our findings indicate that the HLE should not only be a target for supporting children's literacy, numeracy, and behavioural development, but that the HLE also influences children's reasoning abilities. Even non-intensive interventions may be sufficient to improve the home learning environment and to support children's cognitive development. Providing parents with general information on the HLE and with specific information about ways in which to support emerging literacy and numeracy skills in a purposeful manner may contribute to the provision of a more favourable learning environment, even on a small budget.

As parents typically interact with their pre-school children frequently and over extended periods of time, focused interventions in the home such as the one used in this study may support the development of children's cognitive abilities. Early childhood educators could provide parents with information about the important impact of the home environment on children's learning, model play-based approaches to support children's mastery of the counting principles and demonstrate the use of dialogic reading strategies. As a nonintensive intervention, this easy-to-apply approach might appeal also to families who due to economical, educational or language constraints often would shy away from other forms of family programs. Consequently, this kind of intervention could be used in different contexts, 
and it could be initiated by educators and teachers, even when not many resources are readily available.

We found that parents in the intervention group made adjustments to the interactions they had with their children at home by purposefully supporting children's ability to analyse, explain and justify their thinking. This requires children to engage in rich and complex thinking. If such adjustments to the quality of interactions at home are sustained over time, one may expect gains in cognitive development to be sustained as well. This would in turn impact on the child's learning trajectory as they commence formal school education and learn to read and write, and learn formal mathematics. Consequently, non-intensive interventions in the family may be sufficient to enhance child development prior to the commencement of school education.

\section{Acknowledgements}

This work was supported by a fellowship within the Postdoctoral Programme of the German Academic Exchange Services (DAAD). 


\section{References}

Au, J., Sheehan, E., Tsai, N., Duncan, G. J., Buschkuehl, M., Jaeggi, S. M. (2001). Improving fluid intelligence with training on working memory: A meta-analysis. Psychonomic Bulletin \& Review, 22, 366-377.

Anders, Y., Rossbach, H.-G., Weinert, S., Ebert, S., Kuger, S., Lehrl, S. \& von Maurice, J. (2012). Home and preschool learning environments and their relations to the development of early numeracy skills. Early Childhood Research Quarterly, 27, 231-244.

Burgess, S. R. (2002). The influence of speech perception, oral language ability, the home literacy environment, and pre-reading knowledge on the growth of phonological sensitivity: A one-year longitudinal investigation. Reading and Writing: An Interdisciplinary Journal, 15, 709-737.

Bradley, R. H., \& Caldwell, B. M. (1980). The relation of home environment, cognitive competence, and IQ among males and females. Child Development, 51, 1140-1148.

Cohrssen, C., Niklas, F., \& Tayler, C. (in press). 'Is that what we do?' Using a conversation analytic approach to highlight the contribution of dialogic reading strategies to educatorchild interactions during storybook reading in two early childhood settings. Journal of Early Childhood Literacy. DOI:10.1177/1468798415592008

Cohrssen, C., Tayler, C., \& Cloney, D. (2014). Playing with maths: Implications for early childhood mathematics teaching from an implementation study in Melbourne, Australia. Education 3-13: International Journal of Primary, Elementary and Early Years Education. DOI:10.1080/03004279.2013.848916

Cooke, B. D., \& Buchholz, D. (2005). Mathematical communication in the classroom: A teacher makes a difference. Early Childhood Education Journal, 32(6), 365-369. doi: 10.1007/s10643-005-0007-5

Department of Education Employment and Workplace Relations. (2009). Belonging, Being and Becoming: the Early Years Learning Framework for Australia (EYLF). Canberra, Australia.

Doyle B. G. \& Bramwell, W. (2006). Promoting emergent literacy and social-emotional learning through dialogic reading. The Reading Teacher 59(6), 554-564.

Evans, J. J., Floyd, R. G., McGrew, K. S., \& Leforgee, M. H. (2001). The relations between measures of Cattell-Horn-Carroll (CHC) cognitive abilities and reading achievement during childhood and adolescence. School Psychology Review, 31(2), 246-262. 
Floyd, R. G., Evans, J. J., \& McGrew, K. S. (2003). Relations between measures of CattellHorn-Carroll (CHC) cognitive abilities and mathematics achievement across the schoolage years. Psychology in the Schools, 40(2), 155-171.

Frumkin, L. A. (2013). Young children's cognitive achievement: Home learning environment, language and ethnic background. Journal of Early Childhood Research. DOI: $10.1177 / 1476718 X 13482272$

Gauvain, M. (2001). The social context of cognitive development. New York: The Guilford Press.

Gelman, R., \& Butterworth, B. (2005). Number and language: How are they related? TRENDS in Cognitive Sciences, 9(1), 6-10.

Gelman, R., \& Gallistel, C. (1978). The child's understanding of number (pp. 77-82). Cambridge, MA: Harvard University Press.

Gunderson, E., \& Levine, S. (2011). Some types of parent number talk count more than others: relations between parents' input and children's cardinal-number knowledge. Developmental Science, 14(5), 1021-1032.

Howell, S. C., \& Kemp, C. R. (2010). Assessing preschool number sense: skills demonstrated by children prior to school entry. Educational Psychology, 30(4), 411-429.

Klauer K. J. (1996). Teaching inductive reasoning: Some theory and three experimental studies. Learning and instruction, 6(1), 37-57.

Klauer K. J., \& Phye G. D. (2008). Inductive reasoning. A training approach. Review of Educational Research 78, 85-123.

Klauer K. J., Willmes, K., \& Phye, G. J. (2002). Inducing inductive reasoning: Does it transfer to Fluid Intelligence? Contemporary Educational Psychology 27, 1-25.

Kleemans, T., Peeters, M., Segers, E., \& Verhoeven, L. (2012). Child and home predictors of early numeracy skills in kindergarten. Early Childhood Research Quarterly, 27(3), 471477.

Kroesbergen, E. H., \& van Luit, J. E. H. (2003). Mathematics interventions for children with special educational needs: A meta-analysis. Remedial and Special Education, 24(2), $97-$ 114.

Lukie, I. K., Skwarchuk, S.-L., LeFevre, J.-A., \& Sowinski, C. (2014). The role of child Interests and collaborative parent-child Interactions in fostering numeracy and literacy development in Canadian homes. Early Childhood Education Journal, 42(4), 251-259.

Mather, N., \& Woodcock, R. (2001). Woodcock-Johnson III Test of Cognitive Abilities. Examiner's manual. Itasca, IL: Riverside Publishing. 
McGrew, K., Woodcock, R., \& Mather, N. (2001). Woodcock-Johnson III Technical Manual. Itasca, IL: Riverside Publishing.

Molfese, V., DiLalla, L., \& Bunce, D. (1997). Prediction of the intelligence test scores of 3to 8-year-old children by home environment, socioeconomic status, and biomedical risks. Merrill-Palmer Quarterly, 43, 219-234.

Niklas, F., Cohrssen, C., \& Tayler, C. (in press). Improving preschoolers' numerical abilities by enhancing the home numeracy environment. Early Education and Development.

Niklas, F., \& Schneider, W. (2013). Home Literacy Environment and the beginning of reading and writing. Contemporary Educational Psychology, 38, 40-50.

Niklas, F., \& Schneider, W. (2014). Casting the die before the die is cast: The importance of the home numeracy environment for preschool children. European Journal of Psychology of Education, 29(3), 327-345.

Niklas, F., \& Schneider, W. (2015). With a little help: Improving kindergarten children's vocabulary by enhancing the home literacy environment. Reading and Writing: An Interdisciplinary Journal, 28(4), 491-508. DOI: http://dx.doi.org/10.1007/s11145-0149534-Z

Schmiedeler, S., Niklas, F., \& Schneider, W. (2014). Symptoms of attention-deficit hyperactivity disorder (ADHD) and home learning environment (HLE): findings from a longitudinal study. European Journal of Psychology of Education, 29(3), 467-482.

Schneider, W., Niklas, F., \& Schmiedeler, S. (2014). Intellectual development from early childhood to early adulthood: The impact of early IQ differences on stability and change over time. Learning and Individual Differences, 32, 156-162.

Sénéchal, M. \& LeFevre, J.-A. (2002). Parental involvement in the development of children's reading skill: A five-year longitudinal study. Child Development, 73(2), 445460.

Sénéchal, M. \& Young, L. (2008). The effect of family literacy interventions on children's acquisition of reading from kindergarten to grade 3: A meta-analytic review. Review of Educational Research, 78(4), 880-907.

Sheldon, S. \& Epstein, J. (2005) Involvement counts: Family and community partnerships and mathematics achievement, The Journal of Educational Research, 98(4) 196-206.

Starkey, P. \& Klein, A. (2000) Fostering parental support for children's mathematical development: An intervention with Head Start families, Early Education and Development, 11(5), 659-680. 
Swanson, H. L. \& Hoskyn, M. (1998). Experimental intervention research on students with learning disabilities: A meta-analysis of treatment outcomes. Review of Educational Research 6(3), 277-321.

U.S. Department of Education. (2007). Dialogic reading. Washington: Institute of Education Sciences; National Center for Education Evaluation and Regional Assistance; What Works Clearinghouse.

Vygotsky, L. (1978). Mind in society: The development of higher mental process. Cambridge, MA: Harvard University Press.

Watkins, M.W., \& Smith, L.G. (2013). Long-term stability of the Wechsler intelligence scale for children - fourth edition. Psychological Assessment, 25,477-483.

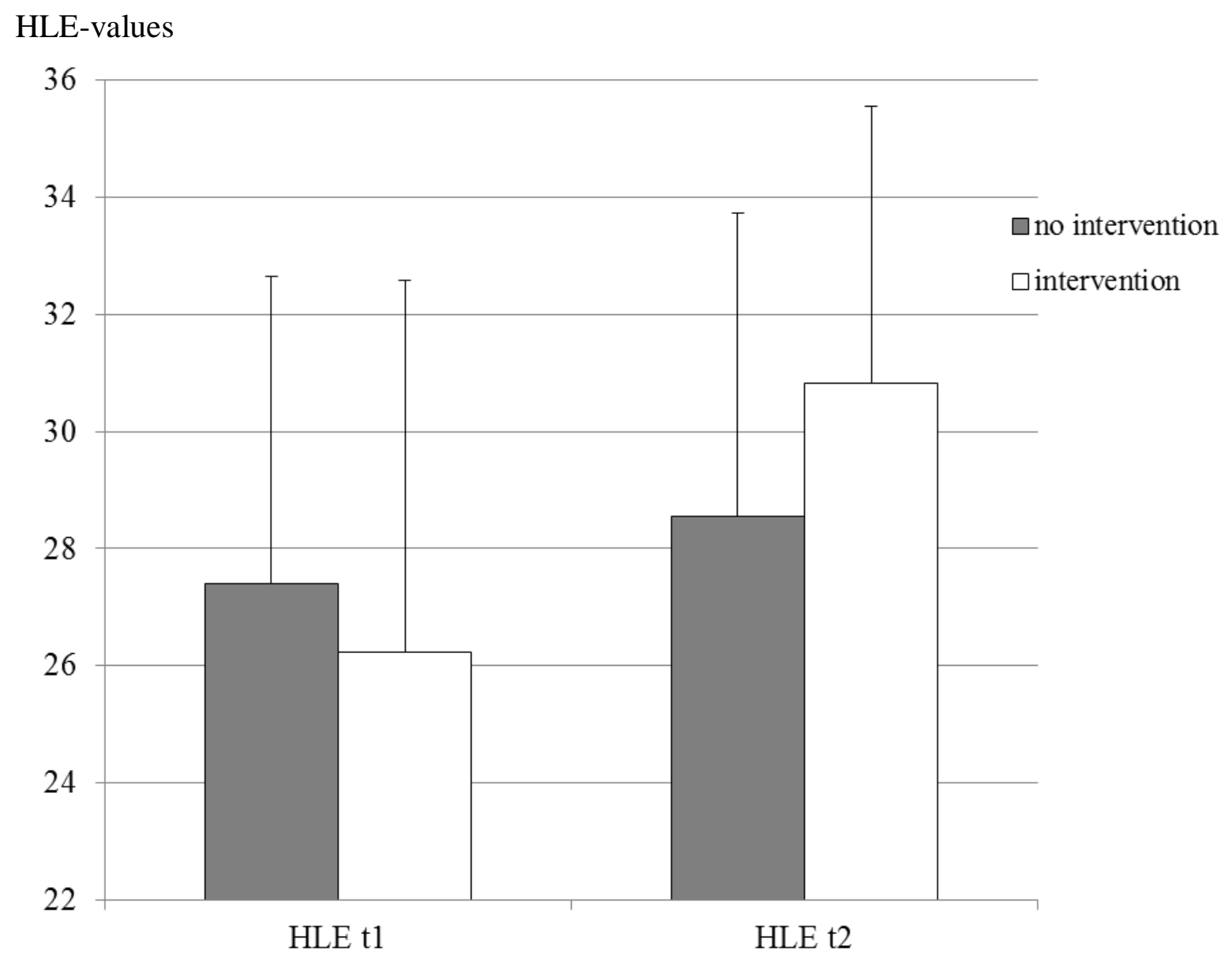

Figure 1: Home learning environment before and after intervention for intervention and nonintervention group 


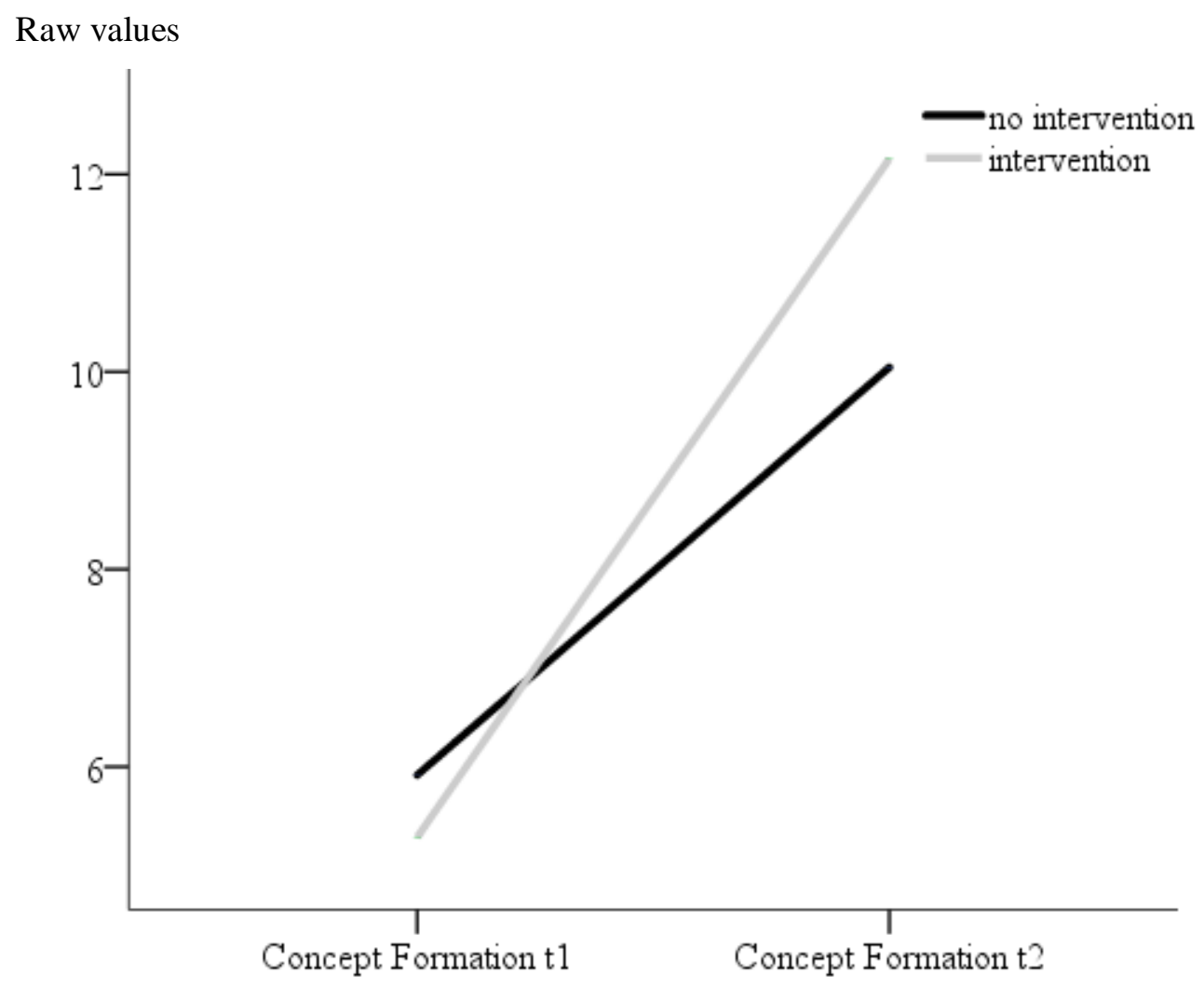

Figure 2: Development of Concept Formation between $\mathrm{t} 1$ and $\mathrm{t} 2$ for intervention and nonintervention group controlled for child age and sex

Table 1: Correlational analyses of the study variables and descriptive statistics for the home learning environment (HLE) and Concept Formation

\begin{tabular}{|c|c|c|c|c|c|c|c|c|}
\hline & 2 & 3 & 4 & 5 & 6 & 7 & 8 & $\mathrm{M}(\mathrm{SD})$ \\
\hline 1. Age at $\mathrm{t} 1$ in months & $.20^{*}$ & .07 & $-.19^{\#}$ & -.04 & .15 & $.21^{*}$ & $.24^{*}$ & $52.65(3.93)$ \\
\hline 2. $\operatorname{sex}(0=q ; 1=\widehat{\jmath})$ & & $-.19^{\#}$ & -.11 & .14 & .02 & .06 & .05 & \\
\hline 3. main language $\$$ & & & .07 & .03 & $-.20^{\#}$ & .14 & .07 & \\
\hline 4. parental education & & & & -.02 & .13 & .12 & .15 & \\
\hline
\end{tabular}


5. HLE $\mathrm{t} 1$

6. HLE t2

7. Concept formation $\mathrm{t} 1$

8. Concept formation $\mathrm{t} 2$
$.64^{* * *} \quad .27^{* *} \quad .24^{*}$

$.20^{\#} .33^{* *}$

$.46^{* * *}$

$10.80(6.02)$

${ }^{\#} \mathrm{p}<.10 ;{ }^{*} \mathrm{p}<.05 ;{ }^{* *} \mathrm{p}<.01 ;{ }^{* * *} \mathrm{p}<.001 ;$

$\$ 0=$ another language than English; $1=$ English as main language

\section{Appendix}

Questions on the Home Learning Environment:

How often do you play games with your child that involve dice?

$\square$ several times a week $\square$ once a week $\square$ every $2^{\text {nd }}$ or $3^{\text {rd }}$ week $\square$ less frequently $\square$ never

How often do you play games with your child that require him or her to count?

$\square$ several times a week $\square$ once a week $\square$ every $2^{\text {nd }}$ or $3^{\text {rd }}$ week $\square$ less frequently $\square$ never

How often do you play games with your child that require him or her to do simple sums?

several times a week $\square$ once a week $\square$ every $2^{\text {nd }}$ or $3^{\text {rd }}$ week $\square$ less frequently $\square$ never

How often do you read (e.g. a book or a newspaper)?

$\square$ daily $\square$ several times a week $\quad \square$ once a week $\square$ rarely $\square$ never

How often do you read to your child?

$\square$ several times a week $\square$ once a week $\square$ ca. once a month $\quad \square$ rarely $\square$ never

How often do you talk to your child about measures such as weight, temperature or speed?

$\square$ several times a week $\square$ once a week $\square$ every $2^{\text {nd }}$ or $3^{\text {rd }}$ week $\square$ less frequently $\square$ never

Tick the appropriate box

not / less /somewhat/ true / very

true true true true 


\begin{tabular}{|l|l|l|l|l|l|}
\hline At home, we often talk about things we have read & & & & & \\
\hline $\begin{array}{l}\text { We often play memory or thinking games at home } \\
\text { (such as Concentration or Snap) }\end{array}$ & & & & & \\
\hline $\begin{array}{l}\text { At home, I often explain my child how to do } \\
\text { simple sums or how to divide for examples apples } \\
\text { to persons or a cake in pieces }\end{array}$ & & & & & \\
\hline $\begin{array}{l}\text { At home, I often explain my child that reading is } \\
\text { done from left to right, what is a word or a } \\
\text { sentence or where a sentence starts and ends }\end{array}$ & & & & & \\
\hline
\end{tabular}




\section{University Library}

\section{- $\mathrm{M}$ IIN E R VA A gateway to Melbourne's research publications}

Minerva Access is the Institutional Repository of The University of Melbourne

Author/s:

Niklas, F;Cohrssen, C;Tayler, C

Title:

Home Learning Environment and Concept Formation: A Family Intervention Study with Kindergarten Children

Date:

2016-09-01

Citation:

Niklas, F., Cohrssen, C. \& Tayler, C. (2016). Home Learning Environment and Concept Formation: A Family Intervention Study with Kindergarten Children. EARLY CHILDHOOD EDUCATION JOURNAL, 44 (5), pp.419-427. https://doi.org/10.1007/s10643-015-0726-1.

Persistent Link:

http://hdl.handle.net/11343/283002 